\title{
Slave Narratives, the Bible and Hymns, Oh My...
}

Religion Text-Mining as a Liaison Service

By Joshua Been, Baylor University Libraries; Bill Hair, Baylor University Libraries

ABSTRACT Learn how theological librarians can forge collaborative enterprises to help integrate digital humanities into academic research and teaching. Coordinating partnerships among digital humanities specialists, faculty, and other researchers allows theological librarians to provide additional services while also enhancing their standing within the academic community. We will highlight specific examples of text analysis, including identifying and visualizing Deuteronomic phrases with African-American slave narratives, and visualizing similarities between George Whitefield's sermons and hymns. We will share and demonstrate custom-developed applications and methods to help theological librarians quickly get started in digital humanities. We look forward to sharing with you our successful collaborative endeavors.

\section{ARTICLE}

Are libraries still the "the heart of the institution," and are we librarians still "the keepers of the sacred flame?" Each year we strive to justify our continued existence to top administrators because our governing boards press us to justify the skyrocketing expense of maintaining our academic/theological libraries. Sure, everything is not freely available on the internet, but why and from where did this fallacy arise? We librarians must shoulder some, if not most, of the blame, as we all could have done better jobs to educate our constituents regarding the truth about electronic resources. As our collections' landscape has changed from print to electronic, we have made the transition so simple and seamless that in many cases our clients 
do not know the difference between the "free" internet and the very expensive databases to which we subscribe. It is up to us librarians to adapt and change our roles in the academy. Failure to find ways to partner and collaborate with teaching faculty colleagues is not an option for the long-term survival of our profession.

This leads us to the present moment at George W. Truett Seminary of Baylor University. One year ago, in August 2017, Baylor University Libraries hired a Digital Scholarship Librarian, which, in itself, is not all that unusual, particularly when one assumes most of the work of this librarian will be with liaison librarians in non-theological fields. However, what made this different was the fact that this new Digital Scholarship Librarian wanted to work especially with the Theology \& Philosophy Librarian. Up until that moment, we had never considered that theological disciplines would be candidates for working on anything with the Digital Scholarship Librarian. However, pretty quickly our partnership grew pretty quickly to involve a wide assortment of text-mining research support for seminary and religion faculty at Baylor.

Support for text-mining as a library service can be divided into three tiers. Tier 1 focuses on exploring individual texts or individual bodies of work and can be supported by liaisons with minimal to no training. Tier 2 focuses on exploring the relationships between texts and can be supported by liaisons with some introductory training. Tier 3 is fully customizable and can be adapted to answer very specific research questions. Tier 3 requires a technical expertise that can be challenging for a liaison to attain given their primary responsibilities, leading to a collaborative relationship between liaison and library functional specialists.

“Anyone can do it!" shouts Bill Hair, Religion and Seminary Liaison Librarian. Tier 1 represents introductory text analysis tools that require minimal to no training. Examples of Tier 1 resources include Textalyser (http://textalyser.net/) and Voyant-Tools (https://voyanttools.org/). These two web tools require no downloading or installation and allow copy/paste or document uploading. For individual texts, Textalyser provides analytics such as Complexity Factor, Readability, Average Syllables per Word, Average Sentence Length, and much more. Voyant-Tools contains many more tools and provides visualizations and so may require a bit more exploration of the interface 
before a liaison can confidently support this resource. Tools within Voyant-Tools include Word Clouds, Word Frequency per Document Segment, Topic Modelling, and much more.

While Tier 2 requires some basic training, religion liaisons should be able to accommodate training in these resources to provide support exploring the relationships between texts. A perfect example of a Tier 2 resource is NVivo Plus (https://www.qsrinternational.com/ nvivo/nvivo-products/nvivo-12-plus). NVivo is a commercial product but does offer affordable student licenses (https://www.qsrinternational.com/nvivo/products?pm=Student). NVivo's primary function is its ability to facilitate coding, which is the assignment of keywords to sections of text. These codes can be used to analyze texts, compare texts by comparing the prevalence of codes, and to create thematic visualizations based on assigned codes. Codes in NVivo can be assigned manually, assisted with thesaurus-enhanced keyword searching, and fully automated using NVivo's Automated Theme Analysis.

Sure, researchers can cobble together resources and techniques from the first two tiers to integrate text-mining into their research. However, this approach will often bump up against software limitations and black boxes where software methodology is not transparent, and this often leads to work-around solutions that can limit research questions. Tier 3 represents the fact that programming is the only way to ensure that the tools can be customized to fit the specific needs of the researcher. Examples include customized document similarity analysis, emotional analysis of the language used, and customized parts of speech analysis. Tier 3 requires a religion liaison to partner with a functional specialist with programming and digital humanities experience.

While Baylor University has the resources and structure in place to provide Tier 1 and Tier 2 support by the Religion Liaison, as well as Tier 3 support in collaboration with the Digital Scholarship Librarian, liaisons everywhere can-with very little setup-begin to offer Tier 1 and soon after Tier 2. Remember what Bill Hair said: "Anyone can do it!”

Presentation: http://sched.co/ECfV 